\title{
Leveraging Global Fund investments for health systems strengthening: a qualitative case study on Morocco's Concept Note development
}

Nancy Bolan, ${ }^{1}$ Abdellatif Azzouzi, ${ }^{2}$ Kamal Alami, ${ }^{3}$ Abdelali Alaoui, ${ }^{2}$ Hafid Hachri, ${ }^{4}$ Amina Latifi, ${ }^{2}$ Erin Ferenchick, ${ }^{1}$ Viviana Mangiaterra, ${ }^{1}$ Sylwia Murray, ${ }^{1}$ George Shakarishvili ${ }^{1}$ and Yves Souteyrand ${ }^{5}$

${ }^{1}$ The Global Fund, Geneva, Switzerland (Correspondence to: Nancy Bolan: nbolan@umaryland.edu) ${ }^{2}$ Ministère de la Santé, Rabat, Morocco. ${ }^{3}$ UNAIDS, Rabat, Morocco. ${ }^{4}$ Organisation mondiale de la Santé, Rabat, Morocco. ${ }^{5}$ Organisation mondiale de la Santé, Tunis, Tunisia.

\begin{abstract}
Background: In 2014, the Global Fund to Fight AIDS, Tuberculosis and Malaria (Global Fund) introduced a new funding model. Following notice of their 2014-2016 allocation, Morocco took the bold decision to reallocate its entire allocated investment (US\$ 8029 632) for health systems strengthening (HSS) and submitted a comprehensive request for funding solely for interventions to strengthen the health system.

Aims: To explore the specific barriers and facilitators to Morocco's novel development and submission of a cross-cutting HSS funding request to the Global Fund and to document lessons learned and recommendations for policy and programme leaders interested in leveraging Global Fund investments for health systems.

Methods: A thorough desk review of key documents and 15 in-depth qualitative interviews were conducted with key stakeholders in Morocco in 2017.

Results: In preparation for the funding request, Morocco carried out a comprehensive assessment of the health system, which included extensive dialogue with stakeholders and partners. This action was critical to developing a shared understanding and support for adopting a cross-cutting HSS approach. Despite concerns about potential negative effects of diverting funding from disease-specific programmes, visionary leadership advocated effectively for investing in HSS, and this paved the way for the development of a clear Concept Note requesting Global Fund financial support for the health system more broadly.

Conclusion: Morocco was the first country in the Global Fund's Middle/East North Africa region to invest its entire Global Fund allocation in strengthening the health system. Many important lessons have been learned from this novel experience and these are presented for shared learning. This opportunity for learning is timely as countries begin preparations for the upcoming funding cycle.

Keywords: Global Fund, Morocco, investment, health systems strengthening

Citation: Bolan N; Azzouzi AI; Alami K; Alaoui AB; Hachri H; Latifi A et al. Leveraging Global Fund investments for health systems strengthening: a qualitative case study on Morocco's Concept Note development. East Mediterr Health J. 2020;26(8):957-966. https://doi.org/10.26719/emhj.20.039

Received: 07/03/18; accepted: 05/22/19

Copyright (c) World Health Organization (WHO) 2020. Open Access. Some rights reserved. This work is available under the CC BY-NC-SA 3.0 IGO license (https://creativecommons.org/licenses/by-nc-sa/3.o/igo)
\end{abstract}

\section{Background}

In March 2014, The Global Fund to Fight AIDS, TB and Malaria (Global Fund) introduced a new funding model, which helped to foster the integration of disease control programmes into broader health systems with the aim of increasing overall efficiency of investments, addressing system-wide bottlenecks and maximizing health outcomes for the target diseases, HIV, tuberculosis (TB) and malaria (1). The new funding model introduced 2 strategic shifts in the Global Fund's business model. First, each country received a 3-year funding envelope with the amount based on disease burden, income level and other parameters, and had the flexibility to split the total allocation among HIV, TB and malaria programmes based on self-determined country-specific needs. Second, based on a differentiation approach, countries were giv- en different levels of flexibility to also invest in health systems strengthening (HSS) with the aim of addressing system-wide bottlenecks benefitting the 3 disease programmes and beyond. The new funding model also required a country dialogue process to bring key partners together to explore how the available financial resources could be strategically leveraged for maximum impact.

The Global Fund announced this new funding model to Morocco's Country Coordinating Mechanism (CCM) in a letter dated 12 March 2014 [from the Global Fund to the CCM Chair], detailing funding amounts available for Morocco and proposing cross-cutting HSS funding by either including one or more cross-cutting HSS modules in one or more eligible disease concept notes or by submitting a separate HSS Concept Note for a stand-alone grant. In the letter it is also stated that the Global Fund would 
consider HSS investment by a Band 4 country (higher income, lower disease burden) on an exceptional basis, together with Morocco's funding allocation in the amount of US\$ 8029632 for 2014-2016. The figure was based on Morocco's disease burden and income level. For Band 4 categorization, higher income is defined as above US\$ 2000 gross national income per capita; lower and higher disease burden is based on whether a composite measure of disease burden is below or above a Board-designated level. The letter suggested that the funds be used for TB programming, but noted that Morocco was invited to propose a revised "programme split" which would enable the country to reallocate the funding among the disease components and cross-cutting HSS in the manner that best met the country's identified needs. Any proposed reallocation was to be accompanied by documentation of the decision-making process, endorsement by the CCM and a clear articulation of the rationale for the proposed split.

In response, Morocco submitted a comprehensive Concept Note requesting that the entire proposed amount be reallocated exclusively to HSS support for the 3-year funding cycle. The Concept Note proposed interventions aimed at improving the health system to deliver priority programmes in response to the country's national public health issues $(2,3)$. It was anticipated that the interventions would create a long-term impact by using a systems-based approach to reach those most in need, based primarily on demographics (i.e. underserved populations) and geography (i.e. areas with high disease prevalence).

On review of the initial Concept Note, the Global Fund Technical Review Panel expressed support for the novel request, noting it to be technically sound and strategically focused, identifying strategic gaps in the health system and interventions to contribute to greater efficiencies and improved health outcomes in HIV, TB and reproductive, maternal, newborn and child health (4). However, the Technical Review Panel also noted weaknesses in the initial HSS Concept Note, notably a lack of measurable indicators, benchmarks and timelines to achieve project goals. The Technical Review Panel required that these weaknesses be addressed prior to grant making.

In September 2016, subsequent to submitting acceptable revisions, Morocco was approved for $€ 6143816$ euros for HSS activities, with a grant implementation period of 3 years. The Secretary General's office at the Ministry of Health, having administrative responsibility for the 8 central departments, was proposed and accepted as Principal Recipient of the HSS grant. A management unit was created and placed under the authority of the Secretary General for the implementation of the grant.

While the Global Fund has subsequently articulated it's approach to health systems, such clear policy and technical guidance were not in place at the time and, thus, Morocco's decision was visionary. Morocco was the first country in the Middle East/North Africa (MENA) region to obtain a stand-alone HSS grant prior to the release of the Global Fund's 2017-2022 Strategy, which has placed building "resilient and sustainable systems for health" as a core strategic objective $(5,6)$. At the time of Morocco's application, the Global Fund's strategy included support to HSS. However, with the adoption of the new strategy in 2017, the Global Fund shifted its support from HSS to building resilient and sustainable systems for health to emphasize strong support to community systems. In this study both terms are used. HSS will be used to refer to the Concept Note, and "resilient and sustainable systems for health" (RSSH) will be primarily used throughout this paper to represent the Global Fund's current work on health systems as the term more accurately represents the new approach and terminology.

This case study explores the unique context, process, content and actors, which enabled Morocco to successfully submit a cross-cutting funding request. Key lessons learned and recommendations for policy and programme leaders interested in leveraging Global Fund investments for health systems are also extrapolated here.

\section{Methods}

We employed a 2-stage qualitative methodology to explore the facilitators and barriers of Morocco's development of a cross-cutting HSS funding request to the Global Fund in order to develop a case study that aimed to posit lessons learned for other countries requesting Global Fund investments in the health system. The hypothesis was that the country dialogue process required by the New Funding Model, as well as strong national leadership, were key factors that enabled Morocco to overcome significant barriers which favoured disease-specific priorities over cross-cutting investments.

We applied Walt and Gilson's analytical model for health policy analysis as the operational framework for the case study with analytical attention to 4 interrelated aspects of health policy (actors, content, context and process) (7) in order to better understand the dynamics of the country's decision and subsequent actions. The specific characteristics of a qualitative approach leant themselves to the proposed methodology: a belief in multiple realities; a commitment to identifying an approach to in-depth understanding of the phenomena; a commitment to participants' viewpoints; conducting inquiries with the minimum disruption to the natural context of the phenomenon; and reporting findings in a literary style rich in participant commentaries (8).

First, we undertook an initial desk review of key documents for background information on the contextual drivers, content and process of Concept Note development. The Ministry of Health of Morocco, the Global Fund and technical and financial partners provided 28 documents for review; additional searching identified 5 documents for inclusion in the review. Following this review, we conducted 15 in-depth interviews with key stakeholders in Morocco to better understand the dynamics of the process and the complementary 
roles played by different actors leading to Concept Note development. We developed and utilized a semistructured interview guide, based on Walt and Gibson's analytical model, to gather interview data. Interviews were audio-recorded and data were coded deductively using the model as the framework for content analysis to interpret themes from the data (9). Key stakeholders included Ministry of Health personnel, CCM members, representatives of key populations and representatives of the technical and financial partners involved in the development of the Concept Note and the early execution of the HSS project. In addition, an initial background meeting was held with 3 key staff at the Global Fund Secretariat in Geneva, Switzerland.

The Moroccan Ministry of Health gave permission for qualitative interviews to be conducted to complete this non-medical case study in accordance with the principles of the Declaration of Helsinki. All study participants provided verbal consent after they were informed about the purposes of the study and were assured of the confidentiality of their responses.

\section{Results}

\section{Overview}

A review of key documents allowed for an understanding of the context, content and processes involved in Concept Note development. In-depth interviews provided complementary information on the context and processes, as well as additional rich detail on the facilitators and barriers, with a focus on the role of actors.

\section{Key document review}

The desk review provided an initial window into the health agenda of incremental health system reform in Morocco. The Health Sectoral Strategy 2012-2016 affirmed Morocco's commitment to the principle of primary health care reform as the means to achieve universal health coverage and to strengthen the performance of the health system broadly (3). It reflected the principles articulated in Morocco's new constitution of 2011, which captured the political and social changes sweeping Morocco and the Arab world and enshrined the right to health, the "democratization" of the health sector and gender equity as constitutional rights, in order to assure equal access to health care by all Moroccan citizens. Health system reform, underpinned by the Strategy, aimed to decentralize health administration to the regional level and strengthen health system governance through measures including the promotion of closer collaboration with civil society and the private sector. The primary objective of the reform was to ensure universal coverage/access to a consistent, high quality package of primary care services, based on locally provided family practice, for underserved peripheral areas (2). The Second National Health Conference was held in July 2013 to encourage the participation of all stakeholders and citizens in the health system reform process (8).
Against this promising landscape, the desk review also revealed that Morocco's health system was characterized by numerous gaps and bottlenecks to the provision of quality health services. Despite the improvements in health secured in Morocco over the preceding 20 years, significant challenges remained with regard to inequalities in the provision and use of health services among population groups and regions, and between urban and rural areas. Potential risks existed with emerging and re-emerging diseases and the environmental risks and social problems encountered by vulnerable populations. Disparities disproportionally affected underserved populations and/or marginalized groups (primarily sex workers and clients, men who have sex with men, people who inject drugs, people living with HIV, prisoners, migrant populations and seasonal workers). Approximately one-third of Morocco's population did not have health insurance. The health system was characterized by insufficient systematic organization of care provision at different levels and was unable to assure access to a minimum set of services for target diseases and priority health issues at all levels of the system, including referral mechanisms between levels of care and types of facilities (2). Health system gaps were documented in numerous field-based assessments carried out in preparation for articulating the 2017-2021 Moroccan Health Sector Strategy and developing a funding request to the Global Fund. Assessments were commissioned to examine critical facets of the health system; these included reviews of the national HIV and TB programmes, referral and procurement systems, national laboratory functionality, and partnership with civil society, etc. The WHO and UNAIDS country offices provided support for a number of these consultations (9-14) (in 2014, WHO and the Global Fund signed a Memorandum of Understanding whereby the Global Fund allocates specific funding to WHO to financially and technically support Concept Note development processes). Key gaps in the provision of quality health services were identified in 2015 and are detailed below:

\section{- Service availability:}

- disparities in standardized service availability for people with the priority diseases;

- difficulties in access for vulnerable groups due to geographical, institutional and financial barriers;

- non-functional referral and counter-referral systems resulting in loss to follow-up;

- lack of comprehensive case management for key populations;

- lack of access to quality, standardized care for prisoners, migrants and asylum seekers.

\section{- Human resources for health (HRH):}

- insufficient numbers and uneven distribution of HRH between regions, provinces, urban/rural areas; 
- challenges to full implementation of planned health decentralization related to HRH;

- insufficient quality of care provision;

- absence of a structured plan for strategic management of $\mathrm{HRH}$;

- inadequacy of HRH capacity-building programmes;

- lack of adequate HRH-related data;

- teaching curricula at medical schools not geared towards general medicine/public health.

\section{- Procurement and supply chain management/} laboratories

- poor quantification and inadequate management system for procurement and supply chain management;

- product storage facilities falling short of standards;

- lack of supervision and training of product management staff;

- commodity quality assurance system not sufficiently in place;

- lack of sufficient standardization, oversight, coordination and governance of laboratories.

\section{- Governance:}

- lack of integration and coordination by vertical health programmes;

- limited exposure to results-based planning methods;

- limited inclusion of private or community-based partners in planning;

- limited managerial capacity in decentralized structures;

- limited incorporation of gender approach in health sector terms of responsibilities.

\section{- Surveillance/health information system:}

- lack of integration of parallel vertical programmatic information systems with national system;

- lack of robust information exchange systems and response capacity with laboratories;

- gaps in use of information for decision-making (policies, actions).

\section{- HIV-specific gaps}

- testing provision inadequate in key populations (e.g. sex workers, men who have sex with men, people who inject drugs);

- inadequate prevention of maternal to child transmission (Option $\mathrm{B}+$ ) coverage (estimated at $52 \%$ in 2014);

- expansion of antiretroviral therapy coverage needed (estimated at just $48 \%$ of people living with HIV in 2016);

\section{- TB-specific gaps:}

- dilapidated infrastructure and equipment in certain TB diagnostic and treatment centres;

- high cost of TB medicines;

- shortage of laboratory personnel, programme managers, disparities in distribution of pulmonary specialists;

- gaps in case management, notably with children and with cases lost to follow-up;

- limited TB control cooperation with community and nongovernmental organizations.

\section{- Community systems:}

- insufficient identification of community-based organizations;

- gaps in consistent capacity, quality of work and availability of services in target areas;

- lack of integrated coordination mechanisms between government sector actors and civil society;

- lack of recognition, motivation and training of community workers, leading to high turnover;

- limited involvement of the private sector in service delivery targeting HIV, TB and maternal, newborn and child health.

The request for funding to the Global Fund, thus, sought to fill many of these gaps. The Concept Note development process was led by a steering committee, which included CCM members, Ministry of Health leaders and representatives from the Management Unit for Global Fund TB/HIV programmes as well as WHO and UNAIDS country directors and experts. The HSS Concept Note was drafted over a period of 3 months. Based on the identified bottlenecks, key actions and measures that could potentially be funded by the Global Fund and other financing partners were identified and prioritized for inclusion after a consultative process. Three national dialogues were held, facilitated by 4 technical consultants and supported by the $5 \%$ Initiative and UNAIDS, to reach consensus on the analysis of gaps and to discuss and validate the identified priorities. The $5 \%$ Initiative supported technical assistance with 3 experts: a country dialogue expert, a Concept Note development expert and a budget expert. Their primary objective was to assist Morocco's CCM and the Ministry of Health in preparing the HSS Concept Note by facilitating the 3 country dialogues; they also assisted the CCM in preparing and budgeting the grant according to Global Fund guidelines and incorporating all changes in the final grant document as per the Technical Review Panel's review comments. The dialogues also sought to bring all stakeholders, including key populations, on board towards a common understanding of HSS and the importance of moving beyond vertical programming to address health system bottlenecks in order to improve key disease control efforts. $(15,16)$. 
Documentation revealed a set of criteria, agreed upon by national dialogue participants, to prioritize interventions for inclusion in the Concept Note. This included: alignment with the Sectoral Health Strategy 2012-2016; consideration of the needs of the underserved; adherence to guidelines from the Global Fund for producing the HSS Concept Note; results of regular exchanges and ongoing consultations with the Global Fund country team (e.g. conference calls and country visits); consideration of human rights, gender and basic needs of the key populations and people living with HIV; mapping of available domestic and international funding; complementarity with other funded programmes/ projects aimed at strengthening the health system; and financial resources needed to cover the needs of priority programmes. The final preparatory phase encouraged the integration of comments and remarks from the various stakeholders, and the final draft of the Concept Note included several key content areas that met the above criteria. Main content areas and objectives are described below (17):

\section{- Service delivery}

- represented $58 \%$ (US\$ 4.6 million) of total grant amount;

- promotion of integrated approach through the delivery of minimum packages of activities at the primary health care level;

- promotion of local care/family medicine;

- strengthen referral pathways to ensure continuity of case management and reduce loss to follow-up;

- strengthen the integration of HIV (i.e. prevention of maternal to child transmission) and TB prevention/ curative services at all levels (18).

- Procurement and supply management/laboratory systems

- represented 17\% (US\$ 1.34 million) of total grant amount;

- ensure the availability of essential drugs of high quality and proven efficacy [note: funding for pharmaceuticals primarily from domestic resources (US\$ 250 million in 2014)];

- address funding gaps related to logistics management, infrastructure improvement and quality assurance.

\section{- Human resources for health (HRH)}

- represented 15\% (US\$ 1.2 million) of total grant amount;

- skills development for HRH including community workers;

- address funding gaps related to management and training (i.e. initial and continuing education).

\section{- HSS programme management}

- represented 11\% (US\$ 852 450) of total grant amount;
- strengthen monitoring of RSSH interventions to guarantee efficient implementation/risk management.

\section{Qualitative interviews}

In-depth interviews provided detail on context and process as well as on key barriers and facilitators for Concept Note development and informed lessons learned and recommendations.

National champions advocating for more attention towards HSS articulated that the country had reached the limits of vertical programming with the existing TB/ HIV projects. They strongly believed that the availability of the Global Fund's HSS funding provided a timely opportunity for the country. One stakeholder asserted, "We knew that the way forward would be a health systems approach ... that would tackle specific systemic and cross-cutting bottlenecks, including addressing issues of equity and quality of care." Another said, "The situation is changing, people with HIV and TB have comorbidities and chronic diseases that they need comprehensive care for ... also there is now more mixing of the population with migration and new cultural liberties, so HIV risks may spread to others not normally at risk. We need to go beyond business as usual." Key stakeholders interviewed emphasized that a cross-cutting systems approach would enable a more expeditious reform process leading to more sustainable health interventions for the target diseases laterally across all health programmes, especially given the increased pressure on the health system related to population growth and increased health seeking behaviours. One interviewee noted, "This opportunity came at the right time. We needed these funds urgently in order to face increased demand coming from increased access of the population."

Advocates at the Global Fund described the grant as an opportunity for the country to capitalize on what had been achieved by the HIV and TB programmes to date and to enable the country to take a decisive step forward, in both quantitative and qualitative terms, by removing barriers to prevention and care for the most vulnerable, with an eye towards sustainability. It was also seen as an opportunity for the Global Fund to ensure long-term benefits from the investments it had made in Morocco for over 10 years and demonstrate its commitment to investing in strengthening health systems globally.

The interviewees provided valuable insight on the barriers facing those advocating for a systems approach, notably the reluctance of some in-country stakeholders and Global Fund headquarters staff who questioned the approach with intense scrutiny, and expressed concerns about the potential negative effect on HIV and TB activities as well as the presumed difficulties from a new way of working and the corresponding increases in workload. Stakeholders noted that skilled facilitation and diplomacy was required to convince the communities affected and all partners of the expected benefits of pursuing a more integrated systems approach - compared with a vertical disease-specific approach - and to arrive at a successful 
prioritization of the needs. Additional barriers noted in key stakeholder interviews are summarized below:

- Compressed HSS Concept Note development and project implementation timeline:

- ambitious and condensed preparatory process over 18 months, from the initial communication noting HSS funding opportunities in March 2014 to successful approval of request by the Technical Review Panel in September 2015;

- preparatory consultations conducted on a very tight timeline, given deadlines set by the Global Fund;

- ambitious 3-year implementation timeline for the HSS grant;

- potential of system-wide bottlenecks to impede sustainability of HIV/TB national responses.

- Investment in and negotiation with all parties to support and advocate for HSS:

- need for full collaboration and integration across multiple central Ministry of Health directions and constituents;

- internal scepticism from disease-specific colleagues in the Global Fund Secretariat.

- New procedures and management approaches for all:

- new Global Fund HSS procedures and the technical requirements were challenging;

- new structures required for community involvement in co-management of health facilities;

- incorporating civil society organizations into health system decision-making processes;

- boundaries pushed on discussions about human rights and discrimination;

- complicated context of changing political and cultural norms post-Arab Spring;

- need to strengthen civil society organizations to fill gaps in services to key populations;

- need to bridge cooperation with civil society organizations and to increase capacity and quality of civil society organization partners.

There was consensus among the interviewees that Morocco's success in leveraging Global Fund investments for its health system was in large part due to the vision and advocacy of critical stakeholders, notably the Secretary General of the Ministry of Health, with critical support from senior staff at WHO, UNAIDS and the 5\% Initiative. One individual highlighted, "The Secretary General personally made a presentation to the CCM to demystify the HSS approach and to inform key stakeholders about the timeliness and urgency of this Global Fund opportunity." Other facilitators identified in the interviews included the capacity of the Ministry of Health to take a coordinating role; CCM leadership; and support from key partners, particularly WHO and UNAIDS, who pushed in-country disease- specific colleagues and communities to embrace a health systems approach and committed financial resources to the process. Interviewees discussed how experts at the $5 \%$ Initiative provided timely, high-quality technical assistance, skillfully assisting CCM and Ministry of Health leaders to manage the prioritization exercise for Concept Note development, given the sensitivities involved in making difficult choices. One interviewee noted, "HIV and TB national leadership and key populations had to be willing to consider their priority needs and programmes within a cross-cutting, systems perspective. This was not "obvious or easy". Another said, "Technical and financial partners came together and supported a unique vision, and this was essential."

Additionally, Morocco's Global Fund TB/HIV management unit and the unit coordinator, with 13 years of experience dating back to the early days of Global Fund support, worked in close cooperation with the new HSS Management Unit during the programme start-up period for the purpose of tool sharing and skills transfer and to ensure an integrated approach to activities. Morocco was the first country in the MENA region, and was among the first 7 countries in the world, to receive Global Fund financing in 2003. Further facilitators are summarized below:

- National experience and past achievements:

- Ministry of Health and the coordinator of the Global Fund TB/HIV Management Unit built on 13 years of Global Fund experience;

- previous health system achievements by Morocco aided the process of Concept Note development.

- Leadership by the Ministry of Health:

- personal involvement and commitment of the Secretary General of the Ministry of Health;

- strong support from the Minister of Health;

- target disease national leadership (e.g. National AIDS Control Programme, National TB Control Programme) willing to invest in a cross-cutting approach;

- the HSS programme start-up led by small, skilled HSS management unit

- key committees to monitor the execution of the HSS programme: HSS steering committee (Comité de Pilotage du Programme renforcement du système sanitaire), HSS coordination committee (Comité de Coordination renforcement du système sanitaire) (with bilateral and multilateral donors), and oversight committee (Suivi);

- Significant involvement by key technical partners: WHO, UNAIDS and the $5 \%$ Initiative:

- WHO and UNAIDS country offices participated in the steering committee for Concept Note preparation;

- WHO and UNAIDS country offices supported financially and with technical expertise; 
- 5\% Initiative supported technical assistance with 3 experts.

\section{- Strong leadership by CCM:}

- CCM had over 13 years of experience with Global Fund grant management;

- CCM successfully coordinated an ambitious and condensed HSS preparatory process;

- CCM is involved in the oversight of HSS implementation and monitoring, including field visits.

\section{- Support from the Global Fund Secretariat and the} Technical Review Panel:

- Technical Review Panel approved the entire HSS reallocation request and acknowledged the hard work done;

- Global Fund Morocco Country Team, FPM and RSSH experts supported Morocco from Geneva and through in-country visits, providing guidance into HSS funding options and opportunities.

\section{- Favourable health policy environment:}

- The 2011 Moroccan constitution stated that health is a human right and set a vision of gender equity; the consistency between constitutional rights, health policy as articulated in the Health Sector Strategy (2012-2016) and the HSS Concept Note was important for a harmonized approach;

- HSS programme expanded services for vulnerable populations in line with a human rights approach (planned improvements in health services for key populations included universal access to quality risk reduction services for addiction prevention and treatment for people who inject drugs; addressing inadequate prison health services, including access to HIV/TB services; improving HIV/TB prevention and care for Moroccan police; and increasing access to HIV/TB prevention and care for immigrants/migrants and asylum-seekers);

- national commitment to universal health coverage and primary health care was the driver for health system reform; the creation of a national health insurance programme (RAMED) in June 2012 also increased access to health care.

\section{- Involvement of community partners:}

- the essential contribution made by civil society organizations to health systems acknowledged;

- commitment to developing the capacity of civil society organizations in planning, monitoring and evaluating interventions;

- sense of the urgency to developing a shared vision of partnership with the private health sector, including results/target-based approaches and contracting between the Ministry of Health and private actors;

- commitment to involvement of local public authorities and local private sector for effective mobiliza- tion and efficient use of decentralized funds, which would lend itself to sustainability.

\section{- Strong governance:}

- political stability and transparency in Morocco lent itself to full involvement by donors;

- financial stability facilitated Morocco's contribution via $40 \%$ of project co-funding through transport vehicles, salaries to civil servants, infrastructure, medication procurement and training initiatives;

- strong governance allowed for the timely development of the high-quality HSS Concept Note;

- the transparent process for the choice of Principal Recipient and Sub-recipient included agreement on selection criteria and multipartner elections for Principal Recipient and Sub-recipient selection; transparent democratic procedures were also utilized for the selection of rotating CCM chairs (2003, 2006, 2012);

- a performance-based funding project for 2015-2018 (World Bank \& European Union) signed prior to HSS Concept Note submission, bringing complementarity;

- performance-based funding HSS programmes were planned to improve governance in the health system.

\section{Discussion}

In this case study, we sought to better understand Morocco's process of developing its novel funding request focused on leveraging Global Fund investments to strengthen the health system. We explored barriers and facilitators to the process, in particular the role of divergent actors and a dynamic context. The initial desk review provided necessary background information, while insights gleaned by qualitative interviews enabled a deeper understanding of the issues, including certain insights that would not have been found in published reports. These insights contributed to the formulation of key lessons learned and recommendations, summarized below:

- Be strategic: Targeted investments in key elements of resilient and sustainable systems for health can be used to leverage broader health reforms.

- Country ownership is the foundation: Morocco took a proactive approach to reforming its health system and requesting HSS support from the Global Fund.

- Build upon positive experiences: Morocco built upon its national experience with the Global Fund and past health system achievements.

- Good governance enables action: Stability, transparency and strong governance favoured a high-quality Concept Note and strong grant start-up. 
- Strong leaders champion innovation: Visionary leadership, commitment, innovative thinking and creativity of a small group made a difference.

- Promote equality and equity: Involvement of key populations, young people and women enriched the process.

In the case of Morocco, a collective understanding emerged from the Concept Note development process that investment in cross-cutting interventions could lend critical support towards overcoming specific systemic bottlenecks and more complex systems issues, pushing the country towards improved health coverage of previously under-prioritised populations and towards sustainability of actions. The process of developing a funding request for HSS support and putting the programme in place also served to reinforce national competence to assess and manage cross-cutting initiatives for the long-term for sustainable and costeffective gains (19). This was, and remains, an innovative approach to leveraging Global Fund resources, clearly demonstrating how a systems approach can be used to improve the health of all, including by working towards ending communicable disease epidemics. The example of Morocco further reveals how targeted investments in strengthening key elements of health systems can contribute to integration and leverage broader health sector reforms.

We note 2 main limitations to this study. The interview schedule during the in-country visit was compressed. Additional time would have allowed for field visits and additional interviews, although overall the research approach generated a sufficient amount of data to answer key questions adequately. Additionally, the case study stops short of exploring the implementation period. Future research evaluating the success of the programme would likely reflect additional challenges encountered during the implementation phase of the project and provide further valuable lessons learned.

\section{Conclusion}

The Global Fund's vision has evolved over time to reflect the consensus that strong and effective health systems are a necessary prerequisite for, rather than the outcome of investment in disease control. The new Global Fund Strategy 2017-2022 now explicitly encourages countries to make use of the investments to build resilient and sustainable systems for health, with the aim of reaching more people affected by the target diseases and to increase the overall impact of funding by improving synergies between disease-specific programmes and the primary health care system.

Morocco is a case study of a country that embraced change and leveraged the financial opportunities from the Global Fund to strengthen the health system more broadly, moving beyond traditional disease-specific programming. It set forth an ambitious integrated health systems strategy in order to improve access and quality of health care for all Moroccans. This shift in thinking deviated from the way the country had historically invested Global Fund resources; thus, it required a concerted effort and innovative vision on the part of key stakeholders to advocate for a systems-based approach. Key individuals at the Ministry of Health, WHO and UNAIDS country offices, the $5 \%$ Initiative and the Global Fund Secretariat in Geneva, motivated by a sense of the importance of HSS in the context of Morocco, were also eager to depart from the traditional disease investment model and embrace a new comprehensive systems approach. Collectively, they provided essential support to the process to succeed in moving Morocco and the MENA region forward.

Funding: None.

Competing interests: None declared.

\section{Mobilisation des investissements du Fonds mondial pour le renforcement des systèmes de santé : une étude de cas qualitative sur l'élaboration de la note conceptuelle du Maroc}

\section{Résumé}

Contexte : En 2014, le Fonds mondial de lutte contre le sida, la tuberculose et le paludisme (Fonds mondial) a introduit un nouveau modèle de financement. Suite à la notification de la mise à disposition de leur allocation pour 2014-2016, le Maroc a pris la décision audacieuse de réaffecter la totalité de l'investissement alloué (8 029632 dollars US) au renforcement des systèmes de santé et a soumis une demande de financement globale uniquement pour les interventions allant dans ce sens.

Objectifs : Étudier les obstacles et les facteurs favorables au développement novateur du Maroc spécifiques au pays et examiner la soumission d'une demande de financement transversale au Fonds mondial pour le renforcement des systèmes de santé. Documenter également les enseignements tirés et les recommandations pour les responsables de politiques et de programmes qui souhaitent tirer parti des investissements du Fonds mondial pour les systèmes de santé. Méthodes : Un examen approfondi des documents clés et 15 entretiens qualitatifs approfondis ont été menés auprès des principales parties prenantes au Maroc en 2017.

Résultats: En préparation de la demande de financement, le Maroc a procédé à une évaluation exhaustive du système de santé, qui comprenait un dialogue approfondi avec les parties prenantes et les partenaires. 
Cette action était essentielle pour développer une compréhension et un soutien communs afin d'adopter une approche transversale du renforcement des systèmes de santé. Malgré les préoccupations concernant les effets négatifs potentiels d'un détournement du financement de programmes spécifiques à certaines maladies, des dirigeants visionnaires ont plaidé efficacement en faveur d'un investissement dans le renforcement des systèmes de santé, ce qui a ouvert la voie à l'élaboration d'une note conceptuelle claire demandant au Fonds mondial de soutenir financièrement le système de santé de manière plus générale.

Conclusion : Le Maroc a été le premier pays de la Région Moyen-Orient/Afrique du Nord à investir la totalité de son allocation du Fonds mondial dans le renforcement du système de santé. De nombreux enseignements importants ont été tirés de cette expérience inédite et sont présentés afin de servir à toutes les parties intéressées. Cette opportunité d'apprentissage arrive à point nommé, alors que les pays commencent à se préparer pour le prochain cycle de financement.

$$
\begin{aligned}
& \text { الاستفادة من استثلارات الصندوق العالمي لتعزيز النّّم الصحية: دراسة حالة نوعية حول إعداد المذكرة المفاهيمية } \\
& \text { للمغرب } \\
& \text { نانسي بولان، عبد اللطيف عزوزي، كمال علمي، عبد العالي علوي، إيرين فيرينشيك، حافظ عشري، فيفيانا مانجياترا، سيلفيا موراي، جورج } \\
& \text { شاكريشفيلي، إيف سوتيران }
\end{aligned}
$$

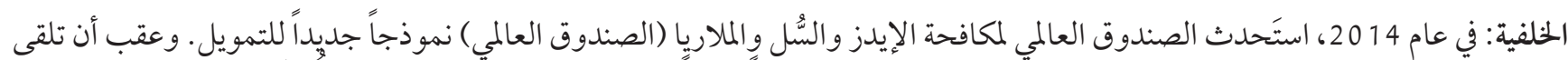

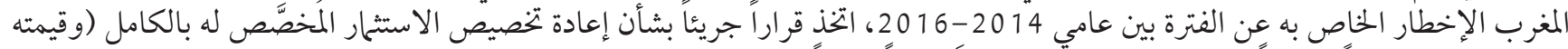

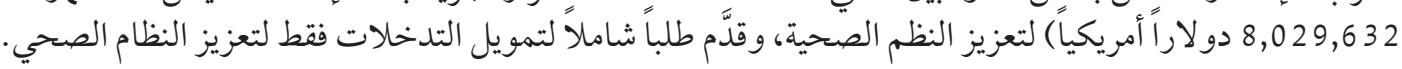

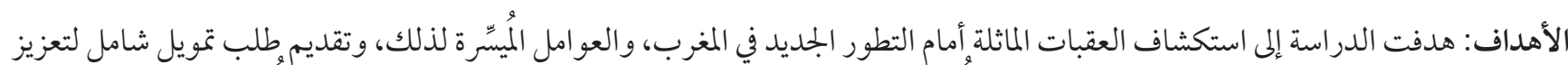

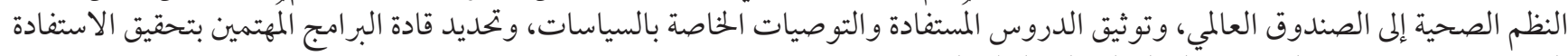
القصوى من استثمارات الصندوق آلعالمي لصالح الصني النظم الصوقية.

طرق البحث: إجراء استعراض مستندي شامل للمستندات الرئيسية و 15 مقابلة نوعية متعمقة مع أصحاب المصلحة الرئيسيين في المغرب في عام

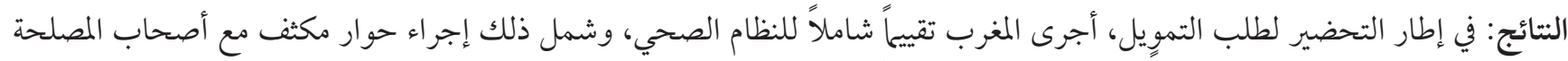

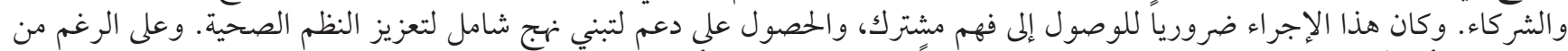

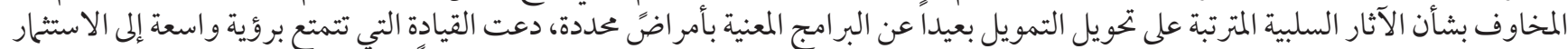

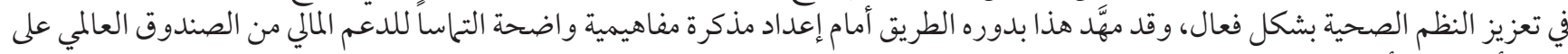
نطاق أوسع من أجل النظام الصحي.

الاستنتاجات: يُعتبر المغرب أول بلد في إقليم الشرق الأوسط/ شمال إفريقيا التابع للصندوق العالمي يقرر استثمار خخصَّصات الصندوق العالمي توني

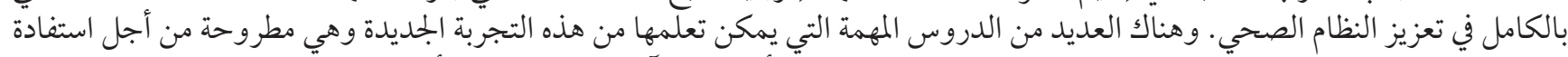

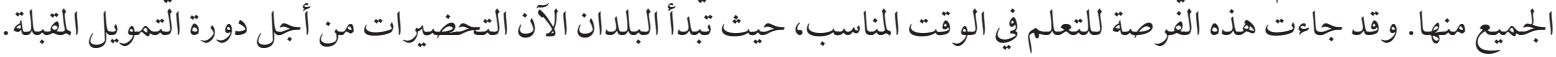

\section{References}

1. The Global Fund's new funding model. Geneva: The Global Fund; 2013 (https://www.theglobalfund.org/media/1467/replenishment_2013newfundingmodel__en.pdf?u=63648680736000000, accessed 20 February 2020).

2. Concept Note for cross-cutting health systems strengthening. Rabat: Country Coordinating Mechanism Morocco; 2015.

3. Stratégie sectorielle de santé 2012-2016. Rabat: Ministère de la Santé, Royaume du Maroc; 2012 (www.sante.gov.ma/Docs/Documents/secteur\%20santé.pdf, accessed 20 December 2018).

4. TRP Concept Note review form, Morocco, cross-cutting HSS. Geneva: The Global Fund; 2015.

5. The Global Fund Strategy 2017-2022: investing to end epidemics. Geneva: The Global Fund; 2016 (https://www.theglobalfund. org/media/1176/bm35_02-theglobalfundstrategy2017-2022investingtoendepidemics_report_en.pdf, accessed 20 December 2018).

6. Building resilient and sustainable systems for health through Global Fund Investments. Information note. Geneva: The Global Fund; 2016 (https://www.theglobalfund.org/media/4759/core_resilientsustainablesystemsforhealth_infonote_en.pdf, accessed 20 February 2020).

7. Walt G, Gilson L. Reforming the health sector in developing countries: the central role of policy analysis. Health Policy Plan. 1994; 9(4):353-70. doi:https://doi.org/10.1093/heapol/9.4.353 
8. Streubert Speziale H, Carpenter D. Qualitative research in nursing: advancing the humanistic imperative, 4th ed. Philadelphia: Lippincott Williams and Wilkins, 2007.

9. Vaismoradi, M, Turunen, H., Bondas, T. Content analysis and thematic analysis: Implications for conducting a qualitative descriptive study. Nurs Health Sci. 2013;15,398-405. doi:10.1111/nhs.12048.

10. 2éme Conférence sur la Santé Juillet 2013. Rabat: Ministère de la Santé, Royaume du Maroc; 2013 (www.maroc.ma/fr/../la-2emeconference-nationale-sur-la-sante, accessed 14 December 2018).

11. National and Souss Massa Draa HIV modes of transmission analysis in Morocco. Rabat: Ministère de la Santé, Royaume du Maroc; 2014 (https://www.researchgate.net/publication/267156880_National_and_Souss_Massa_Draa_HIV_modes_of_transmission_analysis_in_Morocco, accessed 14 December 2018).

12. Mise en œuvre de la déclaration politique sur le VIH/sida. Rapport national 2014. Rabat: Ministère de la Santé, Royaume du Maroc; 2014 (http://www.unaids.org/sites/default/files/country/documents//file\%2C94661\%2Ces..pdf, accessed 14 February 2020).

13. Evaluation basée sur le genre de la riposte au VIH/sida Maroc. Rabat: Ministère de la Santé, Royaume du Maroc; 2014 (https:// maghreb.unwomen.org/fr/ressources-medias/publications/2014/12/evaluation-genre-et-vih-sida, accessed 19 February 2020).

14. Stratégie nationale sur les droits humains et le VIH/sida. Rabat: Ministère de la Santé, Royaume du Maroc; 2013 (http://www. cndh.ma/fr/article/la-strategie-nationale-sur-les-droits-humains-et-vihsida-depasser-les-obstacles-lies-au, accessed 19 February 2020).

15. Compte nationaux de la Sante 2010. Rabat: Ministère de la Santé, Royaume du Maroc; 2010 (http://www.sante.gov.ma/Publications/Etudes_enquete/Pages/default.aspx, accessed 14 December 2018).

16. Santé en chiffres 2015. Rabat: Ministère de la Santé, Royaume du Maroc; 2016 (http://www.sante.gov.ma/Publications/Etudes_ enquete/Documents/04-2016/SANTE EN CHIFFRES 2015 Edition 2016.pdf, accessed 19 February 2020).

17. Sayah S. Ateliers de concertation avec les parties prenantes pour la validation de la Note Conceptuelle sur le renforcement du système de santé (RSS) au Maroc. Rabat: Ministère de la Santé, Royaume du Maroc; 2015.

18. Appui à la rédaction du cadre d'intervention et de la note conceptuelle Renforcement du Système de Santé. Paris: Initiative 5\%; 2015 (http://www.ici-sante.com/references.php, accessed 14 Dec 2018).

19. Cartographie des modalités de mise en oeuvre de la subvention RSS au Maroc. Rabat: Ministère de la Santé, Royaume du Maroc; 2015 . 